\title{
CONCEPTOS ABSTRACTOS, LENGUAJE E HIBRIDACIÓN
}

\author{
ABSTRACT CONCEPTS, LANGUAGE AND HYBRIDISM \\ Fernando Martínez Manrique \\ DOI: 10.26754 /ojs_arif/arif.202024954
}

\begin{abstract}
RESUMEN
En este artículo abordo el problema de la fundamentación de los conceptos abstractos, es decir, cómo se pueden anclar en la experiencia. Argumentaré que, incluso si los enfoques modales, corporeizados, de la cognición son capaces de remitir la adquisición de los conceptos abstractos a tipos diferenciados de experiencias en el mundo, siguen teniendo un problema con la representación mental adecuada para su articulación Haré un breve recorrido del tratamiento que reciben los conceptos abstractos en algunas teorías influyentes que dividiré en dos grandes grupos: enfoques unitarios y pluralistas. Aunque la investigación actual apunta hacia los enfoques pluralistas como los más plausibles, sigue existiendo un problema para dar cuenta de cómo estas diferentes representaciones se combinan entre sí. Explicaré esto en términos del problema de la combinación de conceptos concretos y abstractos. Tras presentar la noción de concepto híbrido, argumentaré que, frente a la estrategia de "hacer concreto" lo abstracto que es habitual en los enfoques de cognición corporeizada, existe la alternativa de "hacer abstracto" lo concreto y que esta estrategia puede ser más acorde con la propia naturaleza de las propiedades abstractas.
\end{abstract}

PALABRAS CLAVE: Abstracto/concreto, amodal/modal, conceptos, corporeización, hibridación

\section{ABSTRACT}

The topic of this paper is the problem of abstract concept grounding, i.e., how they can be grounded in experience. I argue that, even if modal, embodied approaches can refer concept acquisition to distinct types of world experiences, they still have a problem accounting for the suitable mental representations that articulate them. I will offer a brief panoramic of treatments of abstract concepts in some contemporary theories that I will divide into two groups: unitary and pluralistic. Even though current research points towards pluralistic approaches as the most plausible ones, there is still a problem to explain how the plurality of representations are combined. I will present 
this in terms of the combination of concrete and abstract concepts. I will argue that, in contrast to the abstract-to-concrete strategy, a concrete-to-abstract strategy is possible. This strategy may be well in accordance with the nature of abstract properties themselves.

KEYWORDS: Abstract/concrete, amodal/modal, concepts, embodiment, hybridism

\section{INTRODUCCIÓN}

De acuerdo a una concepción generalizada, los sustantivos se pueden dividir en conceptos y abstractos. La división parece tan básica que una niña cualquiera de Cuarto de Primaria la estudiará junto a otras clasificaciones de su libro de Lengua, como las que los divide en contables e incontables, o en individuales y colectivos. Como ejemplos de sustantivos concretos uno puede encontrar 'casa', 'elefante' o 'ángel'; como ejemplos de abstractos, 'miedo', 'belleza' o 'paz'. Extrañamente, para tratarse de una clasificación basada en propiedades semánticas, los manuales no la extienden hacia adjetivos y verbos. Pero, en principio, no debería haber problema en hacerlo. Así, 'rojo', 'triangular' o 'sucio' serían presumiblemente adjetivos concretos, mientras que 'bueno', 'falso' o 'imposible' serían abstractos. Por su parte, 'correr', 'hablar' o 'empujar' serían verbos concretos, mientras que 'esperar', 'comprender' o 'amar' serían abstractos.

¿Cómo se explica a los niños esta distinción? Si uno bucea entre las numerosas páginas web dedicadas a este asunto, encontrará un cierto consenso, con pequeños matices, en caracterizar a los sustantivos concretos como aquellos que designan entidades físicas, materiales, reales, que se pueden percibir por medio de los sentidos. Esta definición dejaría fuera a los ángeles y unicornios, así que algunos la amplían a los nombres de entes que podemos imaginar, donde esto se entiende generalmente como una forma de visualización. (El eslogan podría ser: "si usted puede dibujarlo, es concreto”). A pesar de todo, la distinción sigue siendo difusa, como muestran las preocupaciones de la gente al preguntar en diversos foros si son concretos o abstractos términos como 'guerra', 'tiempo', 'mundo' o 'dolor'. Los esforzados lingüistas que se toman la molestia en responder aclaran que esta

1 En la medida de lo posible, seguiré la convención de utilizar las comillas simples para referirme a entidades lingüísticas ('paz'), las mayúsculas pequeñas para los conceptos (PAZ) y las cursivas para referirme a las propiedades $(p a z)$. Con esto no quiero dar entender que la distinción entre estos tres planos no sea problemática. 
dicotomía, heredada de la gramática tradicional, no responde a ningún criterio lingüístico y que no corresponde a su disciplina resolverla. Que persista en los libros de texto actuales sería uno de esos residuos de los que es difícil librarse. Tampoco sirve de mucho decir que entre lo concreto y lo abstracto hay una gradación y que los términos sobre los que la gente consulta se encuentran en algún punto intermedio de la misma. El problema es que uno tiene que dar con un criterio sobre el que establecer la gradación y no resulta claro cuál sea ese. ¿Prima más la "materialidad" o la "visualizabilidad"? ¿Es visualizable "felicidad' por medio de un smiley? Los filósofos consideran los objetos matemáticos como paradigmas de objetos abstractos (Rosen 2020), ¿significa esto que ‘triángulo’ es un sustantivo abstracto?

La discusión sobre si ' $x$ ' es concreto o abstracto no pasaría de ser un entretenimiento inofensivo, algo para llenar los ratos de sobremesa, como las discusiones sobre si la fresa es o no una fruta, si no fuera por el interés que esta distinción suscita en dos disciplinas. Una es la filosofía, para la cual el modo en que caractericemos lo abstracto parece relevante de cara a establecer una ontología rigurosa que nos permita decir qué son los objetos abstractos, si es que existen ${ }^{2}$. Nótese que el modo típico de establecer la diferencia entre nombres concretos y abstractos remite a alguna diferencia entre los tipos de objetos denotados. La dicotomía apuntaría entonces hacia una distinción fundamental y es tarea del filósofo analizarla de un modo más preciso, que permita discernir qué es lo que tienen en común ciertos tipos de objetos para ser caracterizados como concretos o abstractos. El carácter difuso de la definición tradicional puede disculparse en la medida en que está orientada a niños de 10 años, una edad demasiado temprana para iniciarse en la metafísica.

La segunda disciplina a la que la distinción concreto/abstracto le suscita un interés particular es la psicología. Los psicólogos llevan décadas investigando cómo formamos, manipulamos y combinamos conceptos, al categorizar la realidad o al razonar. Una de las cuestiones que ha originado un buen número de trabajos es la diferencia que parece existir entre conceptos concretos y abstractos. De acuerdo a Borghi et al. (2017), hay dos aspectos que caracterizan de manera única a los conceptos abstractos. Uno es su naturaleza relacional, es decir, el hecho de que vengan caracterizados por sus relaciones con otros conceptos. El segundo es su heterogeneidad: los tipos de propiedades que caracterizan a sus miembros son más diversos y el contexto desempeña un papel importante a la hora de conectarlas. Los conceptos abstractos parecen presentar dificultades específicas, muy en

2 Este es el proyecto detrás del volumen de Falguera y Martínez-Vidal (2020). 
particular para los enfoques afines a la cognición corporeizada (Barsalou et al. 2003). De acuerdo a la concepción de la cognición corporeizada ${ }^{3}$ el significado está constitutivamente ligado a las experiencias sensomotoras del propio cuerpo. Cuando uno piensa en $\mathrm{X}$, simula los estados perceptuales, motores o emocionales vinculados a su experiencia de $\mathrm{X}$. Esto es fácil de comprender cuando $\mathrm{X}$ refiere a entidades como peras o cuchillos, con las que uno tiene una interacción mediada por la visión o el olfato, que puede agarrar o esquivar, que pueden proporcionarle una experiencia placentera o dolorosa. Pero plantea mayores problemas cuando se trata de entidades que las que uno no tiene una conexión sensomotora inmediata, como libertad, coseno o universo.

Un recurso típico para tratar con lo abstracto es el lenguaje. Parece obvio que muchos conceptos abstractos remiten a relaciones que solo pueden hallarse en una rica red de conexiones entre palabras. De manera que es natural postular que su representación ${ }^{4}$ en la mente está relacionada con las representaciones lingüísticas. Ahora bien, decir qué constituye una representación lingüística tampoco es algo que esté exento de problemas. Durante mucho tiempo se consideró que el lenguaje era el paradigma de representación amodal, es decir, un sistema de símbolos completamente desligados de las propiedades sensoriales de las entidades a las que hacen referencia. Frente a esto, la cognición corporeizada ha puesto el foco en los aspectos perceptuales del lenguaje (sus características visuales y auditivas), así como en sus aspectos interactivos (su relación con la acción y las prácticas sociales en general). En la medida en que lo perceptual y lo interactivo sean susceptibles de recibir un tratamiento corporeizado, el recurso al lenguaje permitiría una puerta de entrada de lo abstracto afín al tratamiento que ya reciben los conceptos concretos.

En este artículo me propongo revisar las perspectivas de esta posición. En primer lugar, plantearé el problema de la fundamentación de los conceptos abstractos, es decir, cómo se pueden anclar en la experiencia. La fundamentación remite en realidad a dos problemas diferentes: el tipo de experiencia en la que se puede basar la adquisición de un concepto abstracto; el tipo de articulación en la que se

\footnotetext{
3 No existe consenso a la hora de fijar un término en español para el inglés embodied. Uno puede encontrar las opciones 'corpórea', 'corporizada', 'incorporada' o 'encarnada' adoptadas en diversos escritos.

4 En este artículo asumo la tesis representacionalista, según la cual un concepto es un tipo de representación mental (Laurence y Margolis 1999), no un tipo de objeto abstracto o un tipo de habilidad (Margolis y Laurence 2007). Además de mis propias convicciones al respecto, lo cierto es que este es un supuesto común a la mayoría de los autores involucrados en el debate, i.e., que lo que está en cuestión es el tipo de representación que constituye un concepto.
} 
basan las combinaciones con conceptos abstractos. Argumentaré que, incluso si los enfoques modales de la cognición son capaces de remitir la adquisición de los conceptos abstractos a tipos diferenciados de experiencias en el mundo, siguen teniendo un problema con la representación mental adecuada para su articulación. A continuación, haré un breve recorrido del tratamiento que reciben los conceptos abstractos en algunas teorías influyentes. Para ello las dividiré en dos grandes grupos, que llamaré enfoques unitarios y enfoques pluralistas. En los unitarios, el tipo de representaciones constitutivas de los conceptos abstractos no se distinguen de las de los concretos; en los pluralistas, los conceptos abstractos requieren un tipo diferente de representación. Como veremos, las evidencias de la investigación actual apuntan hacia los enfoques pluralistas como los más plausibles. Sin embargo, señalaré que sigue existiendo un problema para dar cuenta de cómo estas diferentes representaciones se combinan entre sí. Explicaré esto en términos del problema de la combinación de conceptos concretos y abstractos. Tras presentar la noción de concepto híbrido, argumentaré que, frente a la estrategia de "hacer concreto" lo abstracto que es habitual en los enfoques de cognición corporeizada, existe la alternativa de "hacer abstracto" lo concreto y que esta estrategia puede ser más acorde con la propia naturaleza de las propiedades abstractas.

\section{EL PROBLEMA DE LA FUNDAMENTACIÓN DE LOS CONCEPTOS ABSTRACTOS}

La ciencia cognitiva clásica daba cuenta de lo conceptual en términos de las computaciones de los procesos cognitivos superiores. Los pensamientos tendrían naturaleza proposicional (Pylyshyn 1984) y los conceptos serían los constituyentes de dichos pensamientos. En esta concepción, los conceptos se entienden como símbolos abstractos que representan arbitrariamente su contenido. $O$ por ponerlo en la forma preferida del debate contemporáneo, como representaciones de carácter amodal, que no preservan ningún elemento de las modalidades sensoriales en las que se nos ofrecen los objetos que representan. Concebidos como tales entidades computacionales abstractas, los conceptos son aptos para representar todo tipo de propiedades, las entendamos como concretas o abstractas. Sin embargo, el auge de los modelos de cognición corporeizada ha ido poniendo cada vez más en cuestión esta visión. Una parte de la motivación de estos modelos proviene del estudio de las habilidades conceptuales en tareas de categorización y de razonamiento, donde los hallazgos mostraban que la modalidad sensorial en que se presenta la tarea experimental ejerce una influencia sobre la respuesta de los sujetos (Barsalou et al. 2003). Esto se veía corroborado por la investigación neurocientífica que 
encontraba que en las tareas de tipo conceptual se activan áreas cerebrales involucradas en el procesamiento de la modalidad perceptual asociada a los referentes de los conceptos supuestamente en acción (cfr. Gallese y Lakoff 2005).

Como ocurre con cualquier investigación, los hallazgos de este tipo están sujetos a controversia (Mahon y Hickok 2016). Sin embargo, en un plano más teórico, el enfoque de la cognición corporeizada para los conceptos cobra también ímpetu al presentarse como una solución al llamado problema de la fundamentación

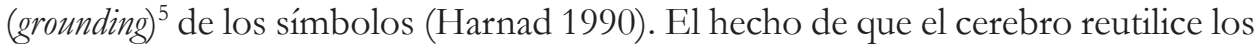
circuitos involucrados en el procesamiento de determinada información parece garantizar que dicha información se fundamenta en experiencia concreta y que podemos remitir su contenido a las propiedades de dicha experiencia. Este tipo de explicación parece funcionar especialmente bien con los conceptos concretos. Pensar, por ejemplo, EL GATO PERSIGUE AL RATÓN recrea las representaciones visuales de los animales y los mecanismos sensomotores involucrados en el movimiento que requiere la acción de perseguir. No obstante, los conceptos abstractos parecen ofrecer especial resistencia a esa estrategia de fundamentación. Uno puede entender en qué consiste recrear o simular la imagen de un gato, pero cuesta más trabajo hacerlo para conceptos paradigmáticamente abstractos como VERDAD, LIBERTAD o INVENCIÓN. Por consiguiente, una parte del esfuerzo investigador del enfoque corporeizado, si aspira a ofrecer una visión unificada de la vida mental, se ha orientado a buscar de qué modo se pueden fundamentar los conceptos abstractos. Así, los tres que acabo de mencionar son los escogidos, por ejemplo, por Barsalou y Wiemer-Hastings (2005) para intentar demostrar que los conceptos abstractos comparten con los concretos lo que ellos llaman contenido situacional. Las diferencias radicarían en las formas situacionales y en la mayor complejidad de los conceptos abstractos, que se encontrarían mucho más distribuidos por las regiones cerebrales que los concretos. La afirmación principal, en cualquier caso, es que los conceptos abstractos también podrían ser simulados al recrear la situación compleja que los fundamenta. Quiero examinar en primer lugar la noción de fundamentación porque creo que se puede distinguir en ella dos cuestiones diferentes, que tienen implicaciones diferentes para el problema de los conceptos abstractos.

${ }^{5}$ Las ideas de corporeizado (embodied) y fundamentado (grounded) están relacionadas pero no son equivalentes (véase Matheson y Barsalou 2018), pero la distinción no es relevante para los propósitos del presente trabajo. 
La primera cuestión es la fundamentación de la adquisición. Es patente que muchos conceptos se adquieren a través del sensorio y que este desempeña ese papel de conexión con la realidad que preocupa a quienes desconfían de que un símbolo abstracto sea algo descorporeizado. En este sentido, la cognición corporeizada se presenta como una variedad de neoempirismo (Machery 2014). Ahora bien, quienes postulan que los conceptos son símbolos amodales no tienen por qué rechazar este tipo de fundamentación. A pesar de que el cognitivismo clásico, probablemente por influencia de Fodor y Chomsky, con frecuencia se asocia a una suerte de racionalismo cartesianismo, la psicología de los conceptos tradicionalmente ha aceptado sin problemas un empirismo "no filosófico" que asume que muchos símbolos deben adquirirse y que la experiencia perceptual es un modo típico de hacerlo. Desde Locke, muchos empiristas han asumido que en la formación de los conceptos a partir de la experiencia sensorial tiene que intervenir algún tipo de abstracción. La abstracción puede entenderse como un proceso en el que se van extrayendo los elementos más destacables de una determinada categoría. Un ejemplo típico de esto es la formación de un prototipo a partir de la exposición a una serie de ejemplares de una categoría. El prototipo es una suerte de representación esquemática que no coincide con ninguno de los ejemplares particulares encontrados y que contiene únicamente la información más discriminativa y diagnóstica con la que comparar futuros ejemplares y determinar si caen o no bajo dicha categoría. Como señala Dove (2016), la abstracción está asociada principalmente al problema de la generalización, es decir, a la cuestión de cómo representar la información que va más allá de la experiencia. Es evidente que el punto de llegada de la abstracción puede perfectamente incluir elementos perceptuales, como una forma, tamaño o color típicos, tal y como se sostiene en el enfoque corporeizado. Sin embargo, la abstracción también podría desembocar, en principio, en un símbolo amodal que no preserve ninguna propiedad específica del referente 6 . El problema está con este "en principio": si el punto de partida es una modalidad sensorial, ¿qué tipo de refinamiento podría dar lugar a un símbolo desprovisto de todo rastro de ella? Como señala Binder (2016, p. 1103), si los conceptos son generalizaciones desde la experiencia (sensorial, motora, afectiva), al

\footnotetext{
6 Probablemente algo de esto tenía Locke en mente al proponer que podemos obtener una idea general de triángulo consistente en "un triángulo ni oblicuo, ni rectángulo, ni equilátero, ni isósceles, ni escaleno" (Ensayo \$14), idea criticada ferozmente por Berkeley. En cualquier caso, la interpretación de lo que sea la abstracción para el propio Locke es controvertida (cfr. Walmsley 1999).
} 
final del proceso de abstracción uno encuentra lo que podríamos llamar representaciones conjuntivas intermodales de alto nivel, capaces de captar conjunciones amplias de información estimular y de retener proporciones variables de los contenidos de la información que proporciona la experiencia. Tales representaciones intermodales no serían análogas a símbolos amodales.

Ahora bien, todo esto supone una dificultad únicamente bajo el supuesto de que el contenido al que interesa referirse es una propiedad concreta. Un modo típico de aprender la categoría de rana implica la capacidad de distinguir visualmente los ejemplares de ranas de los de otros animales. Pero aprender la categoría de democracia no implica la capacidad de distinguir perceptualmente los ejemplares de esta entre otros sistemas políticos. Para fundamentar la adquisición de los conceptos abstractos hace falta una historia más larga, que en muchos casos implica la comprensión de sistemas de relaciones a los que los sentidos dan acceso pero que, a diferencia de la forma de la rana, no remiten a propiedades perceptuales más o menos inmediatas. Si la experiencia sensorial lo que hace es poner en contacto con una propiedad abstracta, vendría a tener un papel de mediación en la constitución de un símbolo que denota dicha propiedad, sin que las propiedades de la propia experiencia tengan reflejo alguno en la naturaleza de dicho símbolo. Los partidarios de la modalidad de los conceptos abstractos tienen por tanto una doble tarea por delante. Por una parte, deben mostrar que hay algún tipo de experiencia sensorial correspondiente a estos conceptos. Por otra, deben mostrar que las propiedades de esa experiencia se preservan en los propios conceptos. (Veremos algunos intentos de mostrar esto en la próxima sección).

La segunda fundamentación que quiero distinguir es la fundamentación del pensamiento. Las consideraciones anteriores llevan a pensar en un modelo en el que a un concepto se le da contenido de manera individual: mis experiencias con un tipo de seres resultan en el concepto RANA y con otros seres en PÁjARO. Ahora bien, poder formar pensamientos sobre las ranas necesita de otro tipo de fundamentación diferente. Por pensamiento entiendo una estructura compleja que combina varios conceptos, como en LAS RANAS SON DISTINTAS DE LOS PÁJAROS. Este pensamiento puede venir por reflexión acerca de las propiedades sensoriales heredadas por los respectivos conceptos. Pero al mismo tiempo va más allá de ellas en el sentido de requerir un tipo de pegamento conceptual que la experiencia sensorial no proporciona: el pegamento composicional que establece una determinada relación entre los conceptos. Esta relación es ella misma una propiedad abstracta que no se encuentra en la experiencia de ranas y pájaros, ni en nuestras recreaciones cuasisensoriales de la misma. ¿En qué se fundamenta entonces esta relación? 
Por ponerlo de otro modo: si la formación de una representación intermodal podía ser el punto de llegada de un proceso de abstracción, no puede serlo sin embargo de un proceso de composición. Formar LAS RANAS SON DISTINTAS DE LOS PÁJAROS no implica únicamente tener un pensamiento que combina las respectivas representaciones modales, sino que esta combinación se haga de una determinada manera especificada por la relación, y esta no está dada en las representaciones modales mismas. La tarea de los partidarios de la cognición corporeizada es, en este caso, ofrecer una explicación acorde a sus principios que diga dónde se fundamenta esta relación.

Como adelantaba en la sección anterior, el recurso principal (no el único, como veremos) para fundamentar los conceptos abstractos es el lenguaje. Pero conviene mantener separadas las dos cuestiones de fundamentación que acabo de señalar para distinguir qué se propone que hace el lenguaje para cada una de ellas. En primer lugar, el lenguaje podría fundamentar la adquisición de los conceptos, en el sentido de que no se pueda aprender concepto alguno si no es por intermediación lingüística. En realidad, al hablar de la abstracción como un candidato a mecanismo genérico de adquisición conceptual, se están planteando las cosas engañosamente, porque se da a entender que es un mecanismo suficiente de constitución del significado. Pero a partir de la misma base de experiencia sensorial se pueden extraer conceptos diferentes, por ejemplo, PÁJARO y COSAVOLADORA-CON-PLUMAS. El problema resulta ser más manejable si consideramos que la abstracción en cuestión va unida a un experiencia lingüística. El lenguaje proporcionaría, entre otras cosas, un sistema de etiquetaje ligado a la experiencia sensorial. Y la etiqueta en cuestión no es un símbolo abstracto, sino un sonido o un signo perfectamente visualizable. La experiencia lingüística es así una experiencia sensorial que amplifica las posibilidades de otras experiencias al permitir asociarlas. Como Lupyan señala (2016, p. 541), no es que las entidades lingüísticas se proyecten sobre conceptos preestablecidos (es decir, establecidos previsamente desde la percepción) sino que el propio lenguaje aumenta la cognición. Esto es tanto más patente cuando se trata de conceptos abstractos, cuyo referente sensorial inmediato es precisamente la palabra que los nombra.

Pero, en segundo lugar, el lenguaje podría fundamentar el pensamiento, en el sentido de que proporcione el pegamento necesario para combinar los conceptos. Sería la capacidad combinatoria del lenguaje la que permitiría ir más allá de la mera intermodalidad, para proporcionar la articulación de los conceptos de manera flexible y abstracta, es decir, desligada de la experiencia. Pero lo que hay que determinar aquí es si dicha articulación también descansa sobre una simulación de experiencias sensoriales, las de las palabras y los contextos asociados a las mismas, o prescinde 
de estas propiedades. En la siguiente sección veremos algunas de las posibilidades que intentan dar cuenta de la fundamentación de los conceptos abstractos.

\section{ENFOQUES UNITARIOS Y PLURALISTAS}

¿Cómo se relacionan los conceptos en la mente? ¿Existe un único sustrato representacional para todos los conceptos o debemos postular más de uno? Llamaré enfoque unitario a aquellas tesis acerca de los conceptos que consideran que todos ellos, con independencia de su contenido o procedencia, comparten una naturaleza común, es decir, están constituidos por el mismo tipo de representaciones. Llamaré enfoque pluralista a aquellas teorías que consideran que los conceptos caen bajo más de un tipo de representación. En esta sección voy a hacer un recorrido rápido por algunas de las teorías más influyentes de estos dos grandes enfoques. El objetivo no es ofrecer una revisión exhaustiva ni un examen de los puntos fuertes y débiles de los mismos, sino un muestrario que sea suficiente para discernir dónde se encuentran las grandes líneas divisorias.

\subsection{Enfoques unitarios}

Sin duda, el enfoque unitario por excelencia acerca de la naturaleza de los conceptos es la tesis del lenguaje del pensamiento de Fodor (1975). De acuerdo a esta tesis, el pensamiento cuenta con un sistema representacional propio, con una sintaxis combinatoria y una semántica composicional. Un concepto es un símbolo mental susceptible de combinarse con otros símbolos mentales de un modo tal que el significado del compuesto es una función del significado de las partes constituyentes. El lenguaje del pensamiento es un sistema paradigmáticamente amodal que no hace distingos entre conceptos concretos y abstractos, es decir, no hay nada en las representaciones conceptuales mismas que dé soporte a esta distinción. Otro aspecto importante de la teoría es el atomismo conceptual (Fodor 1998). Fodor argumenta que la composicionalidad supone un requisito muy exigente para las posibles teorías de conceptos. Todas aquellas teorías que proponen que un concepto tiene una determinada estructura subyacente (un prototipo, ejemplar o teoría que constituye el concepto) son incapaces de dar cuenta de la composicionalidad porque carecen de un criterio para determinar qué elementos de esa estructura son los que se combinan y cuáles son los que se descartan al realizar una composición cualquiera entre conceptos, como en PEZ MASCOTA. Los conceptos son representaciones sin estructura (i.e., átomos) que denotan una determinada propiedad del mundo. Que esa propiedad sea concreta o abstracta, si es que la distinción tiene importancia metafísica, no es algo que interese particularmente a la 
teoría de conceptos. Para Fodor (1998) un concepto es un particular mental que se encuentra enlazado nomológicamente (es decir, de un modo que cae bajo leyes de la naturaleza) con la propiedad que denota. Así PERA denota pera (o la "pereidad", si se prefiere), COSENO denota coseno y PAZ denota paz. No hay diferencias, por otra parte, entre el tipo de representación que constituye PERA, COSENO o PAZ. Las aparentes diferencias residen en el modo de acceso a las respectivas propiedades, lo que Fodor llama mecanismos de sostenimiento. Para ciertas cosas, como las peras, estos mecanismos pueden ser típicamente nuestros sentidos; para otros, como los cosenos, puede hacer falta conocer una determinada teoría, como la trigonometría; para otros, como la paz, se necesita presumiblemente una comprensión de ciertas relaciones sociales. Pero ni la percepción, ni nuestra comprensión teórica o social forman parte constitutiva del concepto mismo: son solo mecanismos que permiten el acceso al enlace nomológico correspondiente. La fundamentación de los símbolos descansa únicamente en el establecimiento de este enlace, no en los mecanismos particulares en los que la mente se apoye para establecerlo. Por tanto, al instanciar un concepto en la mente y combinarlo con otros conceptos, la percepción o la teoría que contribuyeron a sostenerlo no desempeñan ningún papel.

Como ya he dicho, no es el objeto de esta sección evaluar los pros y contras de los enfoques que voy a presentar, pero sí quiero señalar una cuestión pertinente para el análisis de los conceptos abstractos que es el foco de este artículo. La teoría de Fodor permite tratar en pie de igualdad todos los conceptos y parece así deshacerse del problema de la fundamentación de estos. Ahora bien, incluso asumiendo que todos los conceptos se fundamenten en dicho enlace nomológico, queda por ver si existe uniformidad en dichos enlaces. En primer lugar, si entendemos que el enlace es causal y resulta que algunas propiedades son inmateriales, no queda muy claro cómo establecer con ellas enlace causal alguno. Podemos, acaso, establecerlo con la palabra en cuestión, pero esto entraña que el concepto denota una entidad lingüística. En segundo lugar, suponiendo resuelta la cuestión anterior, ¿cómo podemos saber que el enlace causal es el mismo para el caso de las propiedades concretas que para las abstractas? Quizás la causalidad sea más complicada para las segundas y suponga, en último término, alguna diferencia en el tipo de conceptos a los que da lugar. En otras palabras, si se pone en cuestión que el enlace con pera y coseno sea del mismo tipo, habida cuenta de las diferencias entre dichas propiedades, se pone igualmente en cuestión que las diferencias no se reflejen en los conceptos respectivos ${ }^{7}$.

\footnotetext{
${ }^{7}$ Fodor es consciente de que hay un problema metafísico de fondo, de manera que propone una metafísica un tanto tosca para distinguir entre tipos de propiedades, donde la distinción básica es entre propiedades dependientes de la mente e independientes de ella.
} 
Existen otros enfoques unitarios además del de Fodor, que intentan encontrar un sustrato común para todos los conceptos. Una alternativa obvia se encuentra en el lenguaje natural. La idea de que pensamos en nuestra lengua está muy extendida y no falta quien sostiene explícitamente que la formación de conceptos no es otra cosa que la adquisición del lenguaje (Gauker 2011, p. 1). El sistema representacional común para todo tipo de conceptos sería en consecuencia el lenguaje mismo. Esta posición tiene en común con la de Fodor que descarta que los mecanismos de adquisición tengan algún reflejo en la representación que se constituye. Los conceptos concretos y lo abstractos requieren por igual de una representación lingüística, de tal modo que adquirir PERA y PAZ equivale a formar las representaciones internas de las palabras 'pera' y 'paz'. Que la formación de la primera involucre típicamente mecanismos perceptuales y la formación de la segunda presumiblemente no lo haga, no dice nada acerca de la naturaleza de los conceptos respectivos, que se reduce a la de las palabras que uno aprende a manejar.

Dentro de los enfoques que consideran al lenguaje natural como el sustrato representacional común, merecen mención aparte las teorías distribucionales (cfr. Andrews et al. 2014). De acuerdo a estas, el significado se encuentra distribuido en la red de relaciones instituida por las asociaciones entre palabras. De un modo análogo al de los sistemas artificiales que "aprenden" los patrones de un lenguaje a través de cálculos estadísticos de un muestrario lo más grande posible del corpus de una lengua, nuestro cerebro determina el significado a través de un cómputo estadístico sobre esa red de relaciones. Esto vale tanto para el significado de los términos concretos como el de los abstractos y permite, de hecho, entrelazarlos dentro de un mismo tipo de sistema sujeto al mismo tipo básico de procesamiento.

Pero también en el ámbito de la cognición corporeizada es posible encontrar enfoques unitarios. Así, a partir de los hallazgos de efectos de compatibilidad acción-oración, autores como Glenberg y Kaschak (2002), o Glenberg y Gallese (2012) postulan que la representación de los conceptos abstractos activa esquemas de acción análogos a los conceptos concretos. Estos esquemas proporcionarían así un tipo de representación unitaria para ambos tipos de conceptos. También se puede entender como un enfoque unitario la teoría de la metáfora conceptual (Lakoff y Johnson 1980). De acuerdo a esta teoría, la mente estructura nuestro conocimiento de la realidad en base a metáforas, de manera que para comprender un determinado dominio (como el tiempo) recurrimos a otro del que tenemos una experiencia más básica (el espacio) y sobre el que proyectamos metafóricamente las categorías del primero. Así, los conceptos ANTES y DESPUÉS pueden entenderse como relaciones en un espacio en el que nos desplazamos, con el eje 
detrás/delante sirviendo para ubicar el pasado y el futuro respectivamente. Aunque de acuerdo a la clasificación de Borghi et al. (2017) esta teoría establecería diferencias entre los conceptos abstractos y concretos, desde el punto de vista de la base representacional se trata, a mi juicio, de una teoría unitaria que intenta encontrar un fundamento último de experiencias concretas en el que apoyar toda estructura conceptual. Los conceptos concretos serían representaciones corporeizadas, basadas en determinadas experiencias sensoriomotoras que se recrean en la mente al pensar el concepto en cuestión y es en estas experiencias donde proyectamos metafóricamente los conceptos abstractos. No hay diferencias, por tanto, entre el sustrato representacional de un concepto concreto y uno abstracto, solo diferencias en la mayor complejidad de la red metafórica a la que remite el segundo.

\subsection{Enfoques pluralistas}

La investigación actual pone el acento en que nuestra mente trabaja con una variedad de representaciones de diversa índole (Dove 2009). Si existe una diferencia entre los conceptos concretos y los abstractos, sería entonces en términos de las distintas variedades representacionales que sostienen a unos y otros (Borghi et al. 2018, Desai et al. 2018). Diversos autores han apuntado hacia una variedad de factores como responsables de la distinción. Una de las teorías más tempranas al respecto es la teoría de la codificación dual de Paivio (1971). Para este autor la mente cuenta con dos sistemas representacionales básicos: uno basado en imágenes mentales y el otro basado en el lenguaje. El paradigma de las imágenes serían las visuales, pero la noción se extiende a todo tipo de formas de representación perceptual atenuada, como las auditivas o las táctiles, capaces de recrear en la mente un cierto objeto o experiencia. Respecto al sistema basado en el lenguaje, este se entiende generalmente como el lenguaje natural, en forma de habla interna, más que como un código abstracto. Aunque inicialmente orientada a explicar cómo se almacena la información en la memoria, la teoría se fue extendiendo para dar cuenta de las diferencias observadas en numerosos procesos mentales (véase un resumen en Thomas 2020). En líneas generales lo que tenemos no son solo dos clases de representación sino dos tipos de procesamiento diferentes. En relación a la distinción concreto/abstracto, las imágenes mentales se encargarían de codificar lo concreto mientras que lo abstracto sería objeto de representación lingüística (aunque también contaríamos con representaciones lingüísticas de lo concreto).

Esta división de labores básica se mantiene en buena medida en muchos de los enfoques posteriores, particularmente en los afines a la cognición corporeizada 
(de la que Paivio es un antecedente). Sin embargo, el papel del lenguaje se concibe de manera diferente en las distintas posiciones. Por un lado, tenemos a quienes ponen el énfasis en los aspectos puramente perceptuales, como los visoauditivos, de la codificación lingüística. Así, para Prinz (2004) los conceptos son copias de representaciones perceptuales que se diferencian en que los podemos desplegar de un modo independiente de la estimulación inmediata. En línea con la concepción corporeizada, traer a la mente un concepto es recrear la experiencia de la modalidad sensorial en que fue adquirido. Esta experiencia con frecuencia es multimodal: se asemeja más a la recreación de una película que a la contemplación de una foto fija. El lenguaje puede proporcionar la banda sonora de esta película. Los conceptos abstractos, por su parte, recrean palabras insertadas en un contexto situacional. Así, tener el concepto DEMOCRACIA se fundamenta tanto sobre la palabra 'democracia' y la red de asociaciones lingüísticas de la misma, como sobre situaciones evocadas por dicha palabra, tales como las filas de personas delante de una urna. Otros autores extienden el alcance del lenguaje a sus roles funcionales, su capacidad de guiar la acción y la interacción humanas, proporcionando un tipo de experiencia lingüística que no se agota en sus aspectos perceptuales. Así, Borghi y Binkofski (2014) conciben las palabras como herramientas sociales. Pensar conceptos abstractos no consiste en desplegar un determinado tipo de representaciones sino en aprender a manejar esas herramientas para reproducir y manipular con ellas el contexto social. Entre los enfoques pluralistas que recurren al lenguaje no falta quien lo considera un sistema amodal. Así, Dove (2011) señala que aunque el lenguaje se basa en representaciones sensomotoras estas se encuentran "des-corporeizadas".

El lenguaje no es el único factor que se ha señalado para intentar fundamentar los conceptos abstractos. Algunos han puesto el énfasis en los elementos afectivos: la experiencia emocional no solo sería el fundamento de conceptos abstractos como ALEGRía o VERGÜENZA, sino que a través de la misma tendríamos una puerta de entrada a un territorio más abstracto como el de los conceptos morales (Prinz 2007). Otros han destacado el papel de la cognición social, entendida como corporeizada o situada (Smith y Semin 2007). Como Borghi señala, la tendencia actual es tomar en consideración toda esta variedad de elementos representacionales, lingüísticos, emocionales y sociales, y fundamentar en esta variedad toda la diversidad de conceptos abstractos (Desai et al. 2018). No faltan los intentos de sistematizar las clases de conceptos abstractos atendiendo a las propiedades que los sujetos listan como relevantes para caracterizarlos (Harpainter et al. 2018). 
En mi opinión, es difícil hablar de diferentes representaciones como la base de tipos diferentes de conceptos si estas representaciones no están sujetas a tipos diferenciados de procesamiento. En otro lugar (Martínez-Manrique 2014) he defendido la posibilidad de basar la existencia de dos clases de conceptos en dos clases de procesos computacionales. Un tipo de procesamiento al estilo de los sistemas simbólicos clásicos permitiría la combinación de símbolos de manera composicional de manera sistemática y flexible; el otro tipo, que podría estar basado en algo del estilo de los sistemas conexionistas, tendría una composicionalidad circunscrita a la recombinación sistemática de rasgos asociados a una circunstancia ambiental concreta. La teoría de sistemas duales (Evans y Frankish 2009) podría proporcionar la arquitectura básica en la que se inscriben ambos sistemas. En esta concepción existen dos sistemas en los que descansa el razonamiento y el proceso de decisión: S1 es un sistema evolutivamente más antiguo, rápido, basado en procesos asociativos e innaccesible a la consciencia; S2 es un sistema más tardío, lento, basado en procesos seriales y deliberativos, al que tenemos acceso consciente. Es tentador asociar el fundamento de los conceptos abstractos al sistema simbólico clásico y este, respectivamente, al sistema S2 de la teoría de sistemas duales; los conceptos concretos, por su parte, descansarían en procesos como los conexionistas, que podrían ser la base del sistema S1. Creo que hay motivos para resistir la tentación y que las relaciones entre los sistemas son más complejas que lo que este esquema sugiere. De hecho, creo que hay lugar para los conceptos abstractos en ambos tipos de sistemas porque, en un sentido importante, todo concepto incluye elementos abstractos. Para llegar a ello voy a plantear primero un problema que cualquier enfoque sobre los conceptos debe resolver: cómo se combinan los conceptos concretos y los abstractos.

\section{El PROBLEMA DE LA COMBINACIÓN DE CONCEPTOS CONCRETOS Y ABSTRACTOS}

La muestra de posiciones que acabo de presentar no agota todas las concepciones posibles en relación a los conceptos abstractos ${ }^{8}$. Pero creo que es suficiente para mostrar las grandes alternativas. En esta última sección quiero presentar un fenómeno corriente que plantea un problema explicativo a todas ellas. Se trata del fenómeno de la combinación de conceptos concretos y abstractos. Lo cierto es

\footnotetext{
8 Véase Borghi et al. (2017) para una exposición más exhaustiva aunque, como ya he señalado, sus líneas de corte entre posiciones son discutibles.
} 
que con suma frecuencia nuestros pensamientos combinan conceptos que provienen de ambos reinos. Podemos atribuir con normalidad propiedades abstractas a algo concreto, como cuando nos referimos a un perro fiel, o atribuir propiedades concretas a algo abstracto, como al decir que una democracia es débil. ¿Qué es lo que hacemos al producir estas combinaciones? ¿Qué tipo de fundamentación tienen estos pensamientos?

Los enfoques unitarios están mejor posicionados para dar cuenta de las combinaciones de conceptos concretos y abstractos. Al postular un sistema representacional común, nos remiten a principios de combinación generales y uniformes para todos los conceptos, con independencia del contenido de los mismos. Hagamos un recorrido muy sucinto de lo que cada uno de ellos diría que tiene lugar cuando uno piensa sobre una democracia débil. 1) Según el atomismo conceptual, lo que ocurre es que uno produce la composición DEMOCRACIA DÉBIL. En qué sentido las democracias puedan tener la propiedad de ser débiles es una cuestión metafísica que a la teoría de conceptos no interesa. 2) Para la teoría distribucional, uno produce la combinación de palabras 'democracia débil'. Como el significado de cada una de ellas remite a una red de relaciones, al combinar ambas esa red necesariamente cambiará. 3) Para la teoría de metáforas conceptuales, pensar que una democracia es débil hay que inscribirlo en una red metafórica del tipo LOS SISTEMAS POLÍTICOS SON ORGANISMOS, de modo que estructuramos nuestra conceptualización de la democracia proyectando propiedades típicas de un organismo, como la debilidad.

Las concepciones pluralistas tienen que recurrir a otras estrategias para habérselas con estas combinaciones. Supongamos, por simplificar un tanto las cosas, que DEMOCRACIA se fundamenta en la experiencia lingüística y social mientras que DÉBIL lo hace en la percepción de las propiedades de ciertos objetos o en la percepción del propio cuerpo en ciertas condiciones. Si pensar en democracias y en cosas débiles recrea los respectivos fundamentos, ¿qué es lo que se recrea al pensar en una democracia débil? ¿Cuál es, por acudir a la concepción de Prinz, la representación multimodal que combina las modalidades presentes en DEMOCRACIA y DÉBIL? No parece del todo claro que apelar a la posibilidad de unirlas mediante palabras solucione la cuestión: son las propiedades correspondientes a los conceptos DEMOCRACIA y DÉBIL las que no parecen encajar, por mucho que las palabras que los denotan los puedan combinar. Pero, al mismo tiempo, la combinación de estos conceptos es prácticamente trivial, no suscita un problema de comprensión.

En general, la estrategia disponible para los enfoques pluralistas es algo parecida a la de la metáfora conceptual: el modo de entender una combinación de ese 
tipo es atraer el concepto abstracto hacia la órbita del concreto. Así, decir que una democracia es débil es concebir la democracia como una "cosa" que se puede debilitar o fortalecer. A diferencia de lo que sostiene la teoría de metáforas conceptuales, estas maniobras metafóricas no constituyen un sistema: no es necesario que estructuremos nuestra conceptualización de la democracia en términos de la metáfora general LOS SISTEMAS POLÍTICOS SON ORGANISMOS, sino que podemos hacerlo de una manera mucho más puntual y oportunista. Como señala Barsalou (1999), la formación de conceptos no requiere el acceso a un núcleo conceptual que se recupera por defecto sino que se hace de manera ad hoc de acuerdo a las necesidades del contexto. De hecho, uno puede poner en duda que la combinación de conceptos abstracto/concreto tenga que ser necesariamente metafórica en algún sentido interesante. Esto es patente en el caso del perro fiel (que difícilmente es metafórico si uno considera que, después de todo, los perros son uno de los paradigmas de la fidelidad) pero también se puede razonar para el caso de la democracia débil, que sería acaso una metáfora convencional a cuyo contenido tenemos un acceso directo (Martínez-Manrique y Vicente 2013).

La manera habitual de hacer convivir lo concreto y lo abstracto, por tanto, es tratar esto último en términos que resulten afines a lo primero. Después de todo, esta es la idea general de quienes sostienen alguna fundamentación corporeizada de lo abstracto. Voy a sugerir que la estrategia opuesta también es plausible. Y para ello comenzaré con otro tipo de promiscuidad que parece omnipresente en el reino de lo conceptual: en otra parte he defendido, con Agustín Vicente, el carácter híbrido de los conceptos (Vicente y Martínez-Manrique 2016). Un concepto híbrido es una estructura heterogénea compuesta de diversas variedades representacionales organizadas en una unidad funcional. Esta unidad es demasiado "grande" y diversa como para ser manejada en nuestra memoria de trabajo cuando pensamos, o preparamos nuestro pensamiento para ser comunicado. Lo que manejamos son instancias o ejemplificaciones de dicho concepto híbrido, en las que inevitablemente seleccionamos una parte del mismo, de acuerdo a las demandas específicas de la tarea que tengamos entre manos o el contexto comunicativo en que nos encontremos. En algunos casos, esta selección puede tomar la forma de un prototipo, en otros de un ejemplar, en otros de un ideal, etc.

La concepción híbrida puede ayudar a entender por qué de muchos conceptos nos resulta difícil decir si son abstractos o no. Un concepto está constituido por una suerte de amalgama funcional que puede incluir tanto elementos sensoriomotores como no sensoriomotores. Consideremos el concepto PROTÓN: al pensar que los protones están en el núcleo uno puede instanciar imágenes concretas de 
las representaciones visuales prototípicas de un átomo (el clásico núcleo y sus satélites), con el protón ubicado en el centro, mientras que al pensar que los protones son partículas de espín 1/2, uno puede estar manejando sencillamente abstracciones sin ninguna instanciación sensoriomotora, salvo acaso la de las palabras en cuestión. Es razonable pensar que uno "visualice" el protón de una manera ligada a los dibujos que vio para aprender lo que es, y que esta visualización tenga un papel constitutivo en algunas cadenas de pensamiento; pero también lo es que para otros fines uno pueda razonar acerca de los protones sin necesidad de visualizar ni simular nada. Esta misma amalgama de elementos concretos y abstractos se puede observar en una infinidad de conceptos, como GUERRA, TIEMPO, MUNDO o DOLOR, por citar algunos de los discutidos por los internautas. Una guerra ocurre en el mundo físico pero su complejidad hace que la concibamos también de manera abstracta; experimentamos el tiempo a través del cambio físico pero su naturaleza nos resulta ajena y abstracta; el mundo es ciertamente algo físico y perceptible pero demasiado grande para que podamos hacernos cargo del mismo si no es por una abstracción.

Uno podría pensar que saco a colación la hibridación como muestra de la combinación entre lo concreto y lo abstracto, que pueden convivir ecuménicamente dentro de esa estructura funcional. Y que mi objetivo es concluir que proporciona una vía de solución a la cuestión de la combinación concreto/abstracto de la que se ocupa esta sección. Pero esta conclusión no sería correcta: el modo en que lo concreto y lo abstracto (o incluso las distintas variedades de lo concreto) se encuentran asociados dentro de un concepto no es el modo en que necesitamos que se asocien entre conceptos. Lo que une a los distintos elementos que constituyen un concepto híbrido es que sean coactivados de una manera funcional y estable, de tal modo que luego se seleccione el sentido más pertinente para el contexto. Pero lo que une a los conceptos PERro y FIEL o DEMOCRACIA y DÉBIL no es una relación de coactivación, sino una relación de composición.

En otras palabras, como cualquier teoría que postule una pluralidad de representaciones, la hibridación necesita dar cuenta de la composición de aquellas aparentemente heterogéneas. Esta composición se realiza en la memoria de trabajo y allí, como ya se ha dicho, no es el concepto, en toda su heterogeneidad, lo que se combina, sino una instanciación del mismo adecuada al contexto. ¿Qué es lo que se combina en casos como el de DEMOCRACIA DÉBIL? Mi sugerencia es: un componente abstracto en ambos casos. Si los conceptos son híbridos, carece de sentido preguntarse si el concepto X o Y tienen naturaleza abstracta o concreta y su representación es amodal o modal. Una estructura heterogénea puede 
incluir componentes representacionales modales y amodales porque, como se ha dicho, no es necesario articularlas sino meramente mantenerlas asociadas dentro del mismo paquete. Al procesar el concepto para una tarea determinada, se selecciona un componente contextualmente apropiado y es entonces cuando hay que hacer encajar las piezas composicionales. Cabe entonces la posibilidad de que lo apropiado sea seleccionar y combinar los componentes amodales. Al combinar DEMOCRACIA y DÉBIL no es necesario sensorializar el concepto de democracia para entender de qué manera pueda ser débil; antes bien, lo que hay que hacer es de-sensorializar el concepto de débil para ver en qué sentido lo pueda ser una democracia. Esto es posible si tenemos en cuenta que, en realidad, todo concepto se comporta como GUERRA, TIEMPO, MUNDO O DOLOR. Es decir, entre los sentidos de cualquier concepto se cuenta un sentido abstracto e inespecífico, necesario para poder hacer generalizaciones y predicados universales. Seleccionar un sentido inespecífico en un concepto equivale de algún modo a tratarlo como un átomo. Esto no significa darle la razón a Fodor y concluir que el concepto "sea" un átomo, sino más bien concluir que, en determinadas condiciones, la mente puede procesarlo como tal.

Resumiendo, la estrategia de la cognición corporeizada para dar cuenta de los conceptos abstractos es, de algún modo, aproximarlos a los concretos, fundamentándolos en elementos de los que podemos decir que tenemos alguna experiencia sensible, como el ropaje visual o auditivo de lo lingüístico, los sentimientos que acompañan a la experiencia afectiva o la participación en la vida social. Lo que estoy sugiriendo es exactamente lo opuesto: que es posible que para formar ciertos pensamientos haya que aproximar los conceptos concretos a los abstractos y desposeerlos de las características sensoriales específicas con las que normalmente se asocian.

\section{CONCLUSiÓN}

He comenzado este artículo hablando de las dificultades para encontrar un criterio para distinguir lo concreto de lo abstracto y quiero terminarlo revisitando esta cuestión. La investigación psicológica, a mi juicio, no puede proporcionarnos ese criterio pero sí puede darnos algunas pistas de por qué es complicado establecerlo e incluso de qué tipo de investigación ontológica puede ser fructífera para dar cuenta de la naturaleza de los objetos abstractos. En primer lugar, es difícil establecer una distinción porque lo abstracto, al igual que la distinción tipo/ejemplar, está en todas partes. Aunque de manera intuitiva tendemos a incluir 
PÁJARO o COCHE entre los concretos porque tenemos abundantes experiencias de sus ejemplares particulares, lo cierto es que podemos pensar en pájaros y coches en general, sin necesidad de atender a rasgos concretos de los mismos. Si pienso que PRONTO HABRÁ MÁS COCHES QUE PÁJAROS, nada en las características de origen perceptual de dichos conceptos tiene por qué intervenir en mi pensamiento. Estoy tomando las respectivas categorías de manera abstracta para hacer una afirmación general en relación a sus respectivas extensiones. Es cierto que uno puede tener la sensación de que al tener dicho pensamiento acuden a su mente imágenes de coches y de pájaros. (Por así decirlo, contemplo en un lado de mi pantalla mental un montón de coches y en el otro un reducido conjunto de diminutos pajarillos). Puede incluso que esas imágenes sean inevitables: si la concepción híbrida de los conceptos está en lo cierto, el paquete de representaciones que constituye la unidad funcional del concepto PÁJARO se coactiva y en ese paquete las representaciones visuales tendrán una fuerte presencia en conceptos como ese. Pero esos elementos no son lo que se está procesando para formar aquel pensamiento, ni son necesarios para darle significado. De hecho, en muchos casos pensar consiste en sustraerse de esas imágenes asociadas, que irrumpen con la fuerza de los estereotipos, para centrarse en elementos más abstractos. Pensar consiste en seleccionar, dentro de ese conjunto de información que constituye el concepto, aquella más relevante y procesarla de la manera más adecuada para el contexto. Dicho de otro modo, con independencia de que existan o no los objetos abstractos, sí existen representaciones que caracterizan abstractamente una clase cualquiera. En la medida en que es posible hacer esto con todos los conceptos, todos ellos son instanciables como conceptos abstractos?

En segundo lugar, la pluralidad de representaciones implicadas en los conceptos puede inducir a un correspondiente pluralismo de criterios ontológicos al tratar los objetos abstractos. Es decir, no tiene por qué haber un único criterio acerca de estos que nos permita decir qué tienen en común el coseno, el quark, la belleza, la democracia y don Quijote en cuanto objetos abstractos. En casos como el quark, su abstracción no puede tener que ver con la inmaterialidad sino probablemente con su lejanía de la experiencia inmediata, que lo convierte en un objeto material del que solo tenemos constancia a través de una complicada teoría. En casos como la belleza podemos tener que echar mano de nociones como la superveniencia, que permitan entender su dependencia de propiedades materiales

9 Lo cual no implica comprometerse con la existencia de los tipos a los que se refieren los conceptos cuando se utilizan de manera general, como sostiene por ejemplo Wetzel (2009). 
sin reducirla a las mismas, y acaso de respuestas emocionales ante determinadas experiencias perceptuales, mientras que el carácter abstracto de la democracia puede descansar en un intrincado sistema de relaciones sociales. No estoy sugiriendo que la existencia de conceptos presumiblemente abstractos sea la base del análisis metafísico, ni que otorgue ipso facto carta de existencia a aquello a lo que se refieren. Lo que sugiero, más bien, es que apuntan a objetos que, si existen, lo hacen por medio de una serie de apuntalamientos metafísicos tan variados como nuestras representaciones de los mismos.

\section{AgradeCIMIENTOS}

Este trabajo ha sido financiado por la Agencia Estatal de Investigación, en el marco del Proyecto de Investigación de referencia PID2019-108870GB-I00/AEI /10.13039/501100011033, Ministerio de Ciencia e Innovación.

\section{Fernando Martinez Manrique \\ Universidad de Granada \\ fmmanriq@ugr.es}

\section{BIBLIOGRAFÍA}

Andrews, M., Frank, S. y Vigliocco, G. (2014): "Reconciling embodied and distributional accounts of meaning in language". Topics in Cognitive Science, 6, 359-370. http:// dx.doi.org/10.1111/tops.12096

Barsalou, L. W. (1999): "Perceptual symbol systems". Behavioral and Brain Sciences, 22, 577-609.

Barsalou, L. W., Simmons, W. K., Barbey, A. K. y Wilson, C. D. (2003): “Grounding conceptual knowledge in modality-specific systems". Trends in Cognitive Sciences, 7(2), 84-91.

Barsalou, L. W. y Wiemer-Hastings, K. (2005): “Situating abstract concepts". En: D. PECHer, y R. A. ZwaAn, (Eds.), Grounding cognition: The role of perception and action in memory, language, and thinking (pp. 129-163). Cambridge, UK: Cambridge University Press.

BINDER, J. R. (2016): "In defense of abstract conceptual representations". Psychonomic Bulletin \& Review, 23(4), 1096-1108.

Borghi, A. M., Barca, L., Binkofski, F. y Tummolini, L. (2018): "Varieties of abstract concepts: Development, use and representation in the brain". Philosophical Transactions of the Royal Society B: Biological Sciences 373(1752): 20170121

Borghi, A. M. y Binkofski, F. (2014): Words as Social tools: An Embodied View on Abstract Concepts. Berlin: Springer 
Borghi, A. M., Binkofski, F., Castelfranchi, C., Cimatti, F., Scorolli, C. y TummoLINI, L. (2017): “The challenge of abstract concepts". Psychological Bulletin 143(3), 263-292.

Desai R. H., Reilly, M. y van Dam, W. (2018): “The multifaceted abstract brain”. Phil. Trans. R. Soc. B37320170122 http://doi.org/10.1098/rstb.2017.0122

Dove, G. (2009): "Beyond perceptual symbols: A call for representational pluralism". Cognition, 110(3), 412-431.

Dove, G. (2011): “On the need for embodied and dis-embodied cognition". Frontiers in Psychology, 1, 242 doi: 10.3389/fpsyg.2010.00242

Dove, G. (2016): "Three symbol ungrounding problems: Abstract concepts and the future of embodied cognition". Psychonomic Bulletin \& Review, 23, 1109-1121.

Evans, J. ST. B. T. y Frankish, K. (eds.) (2009): In Two Minds: Dual Processes and Beyond. Oxford, Oxford University Press.

Falguera, J. L. y Martínez-Vidal, C. (2020): Abstract Objects: For and Against. Springer.

FoDOR, J. (1975): The Language of Thought. New York: Crowell.

FODOR, J. (1998): Concepts: Where cognitive science went wrong. Oxford: Oxford University Press.

GAllese, V. y LAKOFF, G. (2005): “The Brain's concepts: The role of the Sensory-motor system in conceptual knowledge". Cognitive Neuropsychology, 22, 455-479.

Gauker, C. (2011): Words and images: An essay on the origin of ideas. Oxford: Oxford University Press.

Glenberg, A. M. y Gallese, V. (2012): "Action-based language: A theory of language acquisition, comprehension, and production". Cortex, 48, 905-922

Glenberg, A. M. y KaschaK, M. P. (2002): “Grounding language in action”. Psychonomic Bulletin \& Review, 9, 558-565.

Harnad, S. (1990): “The symbol grounding problem”. Physica D. Nonlinear Phenomena, 42, 335-346.

Harpaintner, M., Trumpp, N. M. y Kiefer, M. (2018): "The semantic content of abstract concepts: A property listing study of 296 abstract words". Frontiers in Psychology, 9: 1748.

Lakoff, G. y Johnson, M. (1980): Metaphors We Live By. Chicago, IL: University of Chicago Press.

Laurence, S. y Margolis, E. (1999): “Concepts and cognitive science”. En: E. Margolis y S. LAurence (Eds.), Concepts: Core readings Cambridge, MA: MIT Press, pp. 3-81.

Locke, J. /1690 /1959). An Essay Concerning Human Understanding. Oxford: Clarendon Press.

LuPYAN, G. (2016): "The centrality of language in human cognition". Language Learning, $66(3), 516-553$.

MACHERY, E. (2014): "Neoempiricism and the structure of thoughts". En: P. CALvO y J. Symons (Eds.) The Architecture of Cognition. Rethinking Fodor and Pylyshyn's Systematicity Challenge. Cambridge, MA: MIT Press, pp. 335-350 
Mahon, B. Z. y Hickok, G. (2016): "Arguments about the nature of concepts: Symbols, embodiment, and beyond". Psychonomic Bulletin \& Review, 23(4), 941-958.

Margolis, E. y Laurence, S. (2007): “The ontology of concepts-Abstract objects or mental representations?", Noûs, 41(4), 561-593.

Martínez-Manrique, F. (2014): "Systematicity and conceptual pluralism". En: P. Calvo y J. Symons (Eds.) The Architecture of Cognition. Rethinking Fodor and Pylyshyn's Systematicity Challenge. Cambridge, MA: MIT Press, pp. 305-334.

MartíneZ-MANRiQue, F. y ViCente, A. (2013): "What is said by a metaphor: The role of salience and conventionality". Pragmatics and Cognition 21(2): 304-328.

Matheson, H. E. y Barsalou, L. W. (2018): "Embodiment and grounding in cognitive neuroscience". Steven's Handbook of Experimental Psychology and Cognitive Neuroscience, vol. 3: Language and Thought. doi.org/10.1002/9781119170174.epcn310

Paivio, A. (1971): Imagery and Verbal Processes. New York: Holt, Rinehart and Winston. (Republished in 1979 - Hillsdale, NJ: Erlbaum.)

PrinZ, J. J. (2002): Furnishing the mind: Concepts and Their Perceptual Basis. Cambridge, MA: MIT Press.

PrinZ, J. J. (2007): The Emotional Construction of Morals. Cambridge, MA: MIT Press.

Pylyshyn, Z. (1984): Computation and Cognition. Cambridge, MA: MIT Press.

Rosen, G.: "Abstract objects", The Stanford Encyclopedia of Philosophy (Spring 2020 Edition), Edward N. Zalta (ed.), https://plato.stanford.edu/archives/spr2020/entries/ abstract-objects/ Consultado el 15-12-2020

Smith, E. R. y SEmin, G. R. (2007): "Situated social cognition". Current Directions in Psychological Science, 16(3), 132-135.

Thomas, N. J. T.: "Mental imagery", The Stanford Encyclopedia of Philosophy (Fall 2020 Edition), Edward N. Zalta (ed.), https://plato.stanford.edu/archives/fall2020/ entries/mental-imagery/ Consultado el 15-12-2020.

Vicente, A. y Martínez-Manrique, F. (2016): “The big concepts paper: A defence of hybridism". The British Journal for the Philosophy of Science 67 (1), 59-88.

Walmsley, J. (1999): “Locke on abstraction: A response to M. R. Ayers", British Journal for the History of Philosophy, 7:1, 123-134, DOI: 10.1080/09608789908571018

Wetzel, L. (2009): Types and Tokens: On Abstract Objects. Cambridge, MA: MIT Press. 